\title{
ADC
}

\section{Socio-economic disparities of childhood body mass index in a newly developed population: evidence from Hong Kong's 'Children of 1997' birth cohort}

C Mary Schooling, Cynthia Yau, Benjamin J Cowling, et al.

Arch Dis Child 2010 95: 437-443 originally published online April 23, 2010 doi: 10.1136/adc.2009.168542

Updated information and services can be found at:

http://adc.bmj.com/content/95/6/437.full.html

\section{These include:}

References This article cites 27 articles, 9 of which can be accessed free at: http://adc.bmj.com/content/95/6/437.full.html\#ref-list-1

Email alerting Receive free email alerts when new articles cite this article. Sign up in the service box at the top right corner of the online article.

Notes

To request permissions go to:

http://group.bmj.com/group/rights-licensing/permissions

To order reprints go to:

http://journals.bmj.com/cgi/reprintform

To subscribe to BMJ go to:

http://journals.bmj.com/cgi/ep 


\title{
Socio-economic disparities of childhood body mass index in a newly developed population: evidence from Hong Kong's 'Children of 1997' birth cohort
}

\author{
C Mary Schooling, Cynthia Yau, Benjamin J Cowling, Tai Hing Lam, Gabriel M Leung
}

Department of Community Medicine and School of Public Health, Li Ka Shing Faculty of Medicine, The University of Hong Kong, Hong Kong SAR, PR China

\section{Correspondence to}

Miss Cynthia Yau, Department of Community Medicine and

School of Public Health, Li Ka Shing Faculty of Medicine,

The University of Hong Kong, Unit 624-627, Level 6, Core F, Cyberport 3, 100 Cyberport Road, Hong Kong, PR China; cynthyau@hkucc.hku.hk

Accepted 6 January 2010

\begin{abstract}
Background Childhood adiposity in developed

countries is often associated with lower socio-economic position (SEP) of the family and neighbourhood. However, the association of adiposity with SEP varies with national income. The authors examined whether childhood BMI was associated with family or neighbourhood socio-economic characteristics in a recently and rapidly developed Chinese population.
\end{abstract}

Methods The authors used multilevel modelling in Hong Kong's population-representative 'Children of 1997' birth cohort $(n=8327)$ to examine the association of $\mathrm{BMI}$ z-score and overweight (including obesity) at ages 6-11 years with parental education, mother's birthplace, sex and neighbourhood median income.

Results In 7108 (85\% successful follow-up) children, boys were more adipose than girls. The association of parental education with BMI z-score varied with mother's birthplace ( $p$ value for interaction 0.001). In children of Hong Kong-born mothers, parental education was negatively associated with BMI z-score (mean difference $-0.15,95 \% \mathrm{Cl}-0.25$ to -0.05 for highest compared with lowest). However, in children of mainland China-born mothers, parental education was positively associated with BMI z-score $(0.18,95 \% \mathrm{Cl} 0.02$ to 0.34 in the same comparison). Neighbourhood had no association with BMI z-score.

Conclusions In this recently developed Chinese population, there was no consistent association between socio-economic characteristics and childhood BMI. Other factors, such as experience of economic transition, as proxied by mother's place of birth, exerted a modifying impact. The cultural and biological mechanisms underlying these socio-historical intergenerational influences need to be determined, so that effective interventions can be implemented in China and elsewhere.

\section{INTRODUCTION}

Adiposity in children is a growing health concern in developing and developed countries. ${ }^{1}$ Precursors to cardiovascular disease (CVD) such as, hypertension, dyslipidaemia and vascular abnormalities are found in overweight children. ${ }^{2-6}$ Childhood obesity tends to track into adulthood, ${ }^{7}$ where it is a risk factor for CVD and for several cancers. ${ }^{7-10}$ Even in slender adults, the cardiovascular risks associated with adiposity are evident. ${ }^{9}$ A higher BMI in childhood is positively associated with ischaemic heart disease (IHD) in adulthood, the effect of which appears to be stronger in boys and increases with age. 8

In long-term developed countries, childhood adiposity is often associated with lower

\section{What is already known on this topic}

Childhood adiposity in developed countries is often associated with lower socio-economic position (SEP) of the family and neighbourhood. However, the association of adiposity with SEP varies with national income.

\section{What this study adds}

- In this recently developed Chinese population, there was no consistent association between socio-economic characteristics and childhood adiposity. Other factors, such as experience of economic transition, exerted a modifying impact. Whether this is due to cultural influences or the biological embodiment of socio-historical influences needs to be determined, so that effective interventions can be implemented in China and elsewhere.

socio-economic position (SEP) both of a family ${ }^{11}$ and of its neighbourhood. ${ }^{11} 12$ However, this does not always extend to minority populations, for reasons which are unclear. ${ }^{13} 14$ Currently, most $(\geq 75 \%)$ young $(<5$ years) overweight or obese children live in low- and middle-income countries. ${ }^{1}$ In adults, the association between SEP and adiposity differs with epidemiological stage, ${ }^{12} 15$ with adiposity becoming associated with lower SEP when the gross national product reaches about US $\$ 2500$ per capita. ${ }^{16}$ The change takes place first in women and then in men, for reasons which are unclear. ${ }^{15}$ In recently developed locations, such as South Korea, SEP appears to be positively associated with adiposity in men, and negatively associated in women. ${ }^{17}$ Thus, the association of low SEP and higher adiposity found in developed countries may not be directly applicable elsewhere, particularly in places at the early stages of economic development or in locations with a recent history of development. It is even less clear how this change in the social patterning of adiposity takes place in children, how quickly it follows economic development, whether it is simply a reflection of national income levels or whether there are other potentially modifiable factors involved. 
Hong Kong has a developed postindustrial economy, whose largely Chinese ( $>95 \%$ ) population has experienced recent and rapid economic development. ${ }^{18}$ The Hong Kong Chinese population was largely formed by migration in the mid-20th century from essentially preindustrial southern $\mathrm{China}^{18}$ to Hong Kong where there was very rapid economic development. ${ }^{19}$ Since the 1980 s, Hong Kong men have increasingly married women from China rather than Hong Kong. ${ }^{20}$ These women have experienced even more recent economic transition, ${ }^{19}$ because socio-economic development in China was very limited before the 1980 s. ${ }^{19}$ Women from mainland China have experienced very rapid socio-economic transition from almost preindustrial conditions to a developed economy over their own lifetime, while women born in Hong Kong have experienced the same transition over perhaps one or two generations. We took advantage of a large, contemporary, population-representative birth cohort in this developed population with a very recent history of rapid economic development to examine several related questions. What was the association of family and neighbourhood SEP with childhood BMI? Did the family's pathway through socio-economic development moderate the associations? Did the associations vary with sex?

\section{PARTICIPANTS AND METHODS}

\section{Setting and subjects: 'The Children of 1997' birth cohort}

The basis of this study is a large, prospective population-representative cohort study initiated in 1997 by the Department of Community Medicine, the University of Hong Kong and the Department of Health, the Hong Kong Special Administrative Region (SAR) Government, to investigate the effects of secondhand smoke exposure on infant health and health service utilisation. ${ }^{21}$ In brief, the sampling frame consisted of all infants born in April and May 1997 brought to one of any of the 49 Maternal and Child Health Centres (MCHC) of the Department of Health for their first postnatal visit. For the index year, $92 \%$ of infants born in Hong Kong visited the MCHC at least once, ${ }^{22}$ which provides free-of-charge preventive care and immunisations. Initially, the study recruited 8327 mother-infant pairs, which corresponded to $88 \%$ of all births during the recruitment period. In 2005-2006, we retrieved additional information from the hardcopy MCHC records, including several additional measures of SEP and anonymous addresses. We also established linkage to routinely available data from the annual Department of Health Student Health Services (SHS) examinations, which enabled us to retrieve all weights and heights measured by trained nurses and recorded to the nearest $0.1 \mathrm{~kg}$ and $0.1 \mathrm{~cm}$, respectively, until the end of March 2009.

Hong Kong is divided into 282 administrative units called Tertiary Planning Units (TPUs), for which census data provide demographic information on neighbourhood SEP. Anonymous addresses were used to assign each child to a TPU. In cases where the TPU could not be assigned from the anonymous address, the address was checked by hand. If the latest address was unavailable, the original address recorded at the first MCHC visit, just after birth, was used.

\section{Exposures}

Highest parental education ${ }^{2324}$ was used as a proxy for family SEP and was categorised as $\leq 9$ th, 10 th to 11 th and $\geq 12$ th grade. TPU median monthly income, taken from the 2001 population census, was used as a proxy for neighbourhood socio-economic characteristics and categorised as $\geq \mathrm{HK} \$ 30000, \mathrm{HK} \$ 20000$ to $<\mathrm{HK} \$ 30000, \mathrm{HK} \$ 10000$ to HK\$20 000 and $<\mathrm{HK} \$ 10000$ (US\$1=HK\$7.8). ${ }^{25}$ Mother's birthplace, recorded on the questionnaire at the baseline interview, was used as a proxy for experience of the economic transition and pathway through socio-economic development, and categorised as Hong Kong or mainland China and other, because most of the mothers not born in Hong Kong were born in mainland China.

\section{Outcomes}

The outcomes were overweight (including obesity) and sex-specific BMI z-score relative to the 2007 WHO growth standards ${ }^{26}$ at ages 6-11 years from annual measurements. Overweight (including obesity) was defined using the International Obesity Task Force (IOTF) cut-offs as equivalent to an adult BMI of 25 or more ${ }^{27}$ because BMI is skewed and so as to be comparable with other studies. The Akima package in $\mathrm{R}$ version 2.6.1 ( $\mathrm{R}$ Development Core Team, Vienna, Austria) was used to interpolate the WHO 2007 growth standards and the IOTF cut-offs to obtain values on the day of measurement.

\section{Statistical analyses}

We used multilevel modelling adjusted for potential confounders to assess the association of SEP proxied by highest parental education and neighbourhood median income with childhood BMI z-scores or the presence of overweight (including obesity), from which mean differences in z-score and ORs, respectively, with $95 \%$ CIs are presented. Children were nested within neighbourhoods when examining the associations with BMI z-score or overweight (including obesity) at specific ages. Multiple measurements were nested by child when examining associations using all available annual measurements from ages 6 to 11 years. Whether the association of highest parental education with overweight (including obesity) or BMI z-score varied with sex and/or mother's birthplace was assessed from the heterogeneity of effect across strata and the significance of interaction terms. We did not adjust for factors associated with SEP and BMI, such as birth weight or breastfeeding, as these may represent some of the intervening processes by which SEP is embodied.

There were 257 (4\%) children missing highest parental education, 1033 (15\%) missing mother's birthplace and 82 (1\%) missing neighbourhood median incomes. Multiple imputation is the statistical gold standard, as the assumptions required for validity of a complete case analysis are a superset of those required for validity of a multiple imputation analysis. ${ }^{28}$ Mother's birthplace, parental education and neighbourhood median income were predicted based on a flexible additive regression model with predictive mean matching ${ }^{23}$ incorporating data on birth order, parental age, housing type, pre- and postnatal secondhand smoke exposure, prematurity status, size for gestational age and BMI z-scores at 3 months. We imputed missing values in those chosen predictors 10 times and analysed the 10 complete datasets separately. We summarised the results into single estimated $\beta$-coefficients or ORs with CIs adjusted for missing data uncertainty. ${ }^{28}$ As a sensitivity analysis, we also carried out a complete case analysis. Statistical analyses were performed using $\mathrm{R}$ version 2.6.1 (R Development Core Team) and Stata version 9.2 statistical software (Stata Corp, College Station, Texas). A p value of less than 0.05 was considered statistically significant. The study obtained ethical approval from the University of Hong KongHospital Authority Hong Kong West Cluster Joint Institutional Review Board and the Ethics Committee of the Department of Health, Government of the Hong Kong SAR. 


\section{RESULTS}

At least one set of height and weight measurements between age 6 and 11 years were available for 7108 children, that is, $85 \%$ of the original cohort, of whom 3357 were girls and 3751 were boys. The mean BMI z-scores at 7 and 11 years for boys were higher than the 2007 WHO standards by 0.3 and 0.5 , respectively (corresponding to 0.5 and $1.1 \mathrm{~kg} / \mathrm{m}^{2}$ higher BMI than the WHO standards). The mean BMI z-score was similar to the standards for girls at 7 years and higher by 0.1 at 11 years (corresponding to $0.3 \mathrm{~kg} / \mathrm{m}^{2}$ higher BMI than the WHO standards). The prevalence of overweight (including obesity) was $18.2 \%$ and $30.4 \%$ for boys at 7 and 11 years, respectively. In girls, the prevalence of overweight (including obesity) was $11.5 \%$ and $17.2 \%$ at 7 and 11 years, respectively.

Figure $1 \mathrm{~A}$ is a visual representation of the median BMI z-score, at 6-11 years in Hong Kong for the TPUs where data were available. The shading corresponds to the value of the TPU-specific median BMI z-score with darker shades representing a higher BMI z-score. For comparison, figure $1 \mathrm{~B}$ shows a visual representation of median income in Hong Kong by TPU. There were no clear areas of high BMI z-score, only sparse patches without any particular pattern, although income had a clear spatial pattern (figure 1B).

Table 1 shows the mutually adjusted associations of highest parental education, neighbourhood median income, sex and mother's birthplace with BMI z-score and the presence of overweight (including obesity) at 7 and 11 years. There was little correlation between highest parental education and neighbourhood (correlation coefficient 0.26 ) or mother's birthplace (0.31). Consistent with figure 1, neighbourhood median income was not clearly associated with BMI z-score or the presence of overweight (including obesity). However, at 11 years, highest parental education was negatively associated with overweight (including obesity).

The association of highest parental education with BMI z-score or overweight (including obesity) at ages 6-11 years varied with mother's birthplace ( $p$ values for interaction 0.001 and 0.003 , respectively as shown in table 2 ), but not with sex ( $p$ values for interaction 0.14 and 0.84 ). The association of mother's birthplace with BMI z-score or overweight (including obesity) also did not vary with sex ( $p$ values for interaction 0.16 and 0.13 ). Table 2 shows the joint associations of highest parental education and mother's birthplace with BMI z-score and overweight (including obesity), adjusted for and stratified by sex, using the offspring of Hong Kong-born mothers with the lowest parental education as the reference. However, there was little evidence that the joint association of highest parental education and mother's birthplace with BMI z-score or presence of overweight (including obesity) varied with sex ( $p$ values for interactions 0.59 and 0.91 ). In the children of Hong Kong-born mothers, there was a negative association of parental education with BMI z-score and overweight (including obesity). In contrast, in the children of China mainland-born mothers, there was a positive association, which was particularly evident for BMI z-score, such that the children of China mainland-born mothers with $\geq 12$ th grade highest parental education had a BMI z-score higher by 0.18 (95\% CI 0.02 to 0.34) compared with $\leq 9$ th grade highest parental education, corresponding to a mean BMI higher by $0.35 \mathrm{~kg} / \mathrm{m}^{2}(95 \%$ CI 0.04 to $0.66 \mathrm{~kg} / \mathrm{m}^{2}$ ). The pattern of associations was fairly similar in boys and girls, with the clearest negative association between parental education and BMI z-score in the daughters

(A)

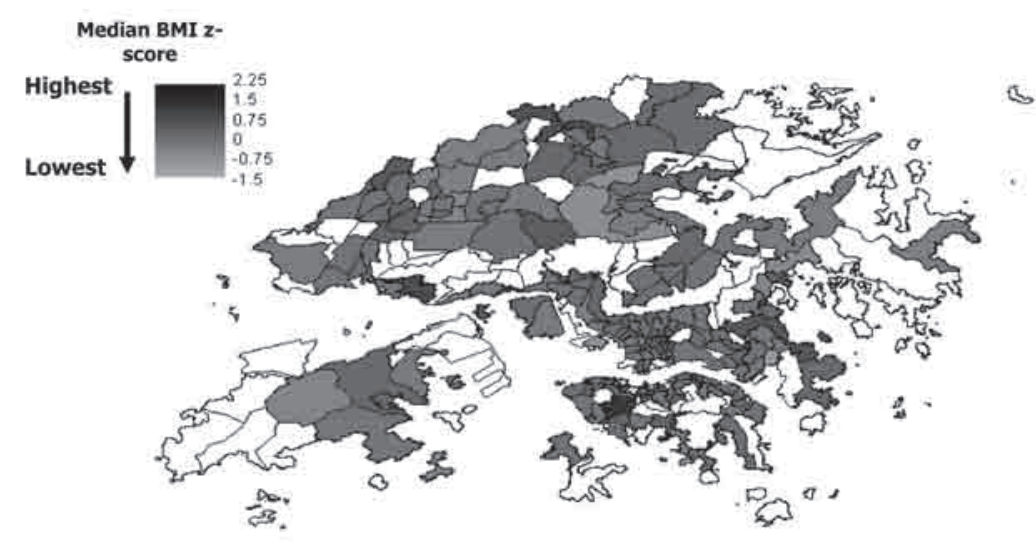

(B)

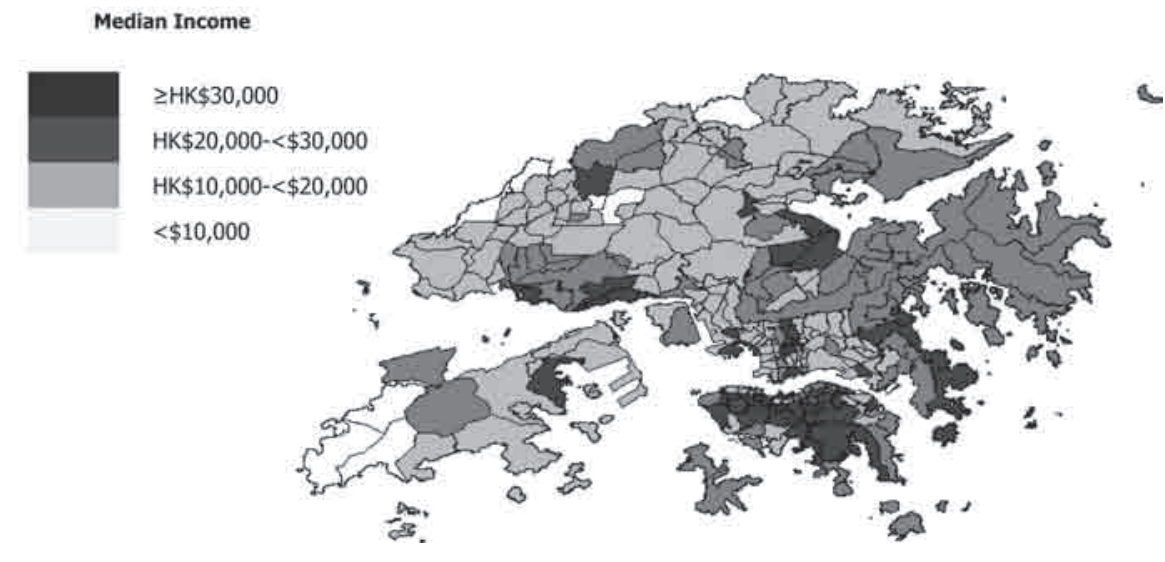

Figure 1 Geographical distribution of (A) median body mass index (BMI) z-score at age 6-11 years in Hong Kong (HK) and (B) median income by tertiary planning units. 
Table 1 Adjusted* associations of sex, socio-economic position and mother's birthplace with BMI z-score and overweight (including obesity) at 7 and 11 years from a multilevel model nested by neighbourhood (tertiary planning units)

\begin{tabular}{|c|c|c|c|c|c|c|c|c|c|c|c|}
\hline & \multirow[b]{3}{*}{$\mathbf{n}$} & \multicolumn{5}{|l|}{7 years } & \multicolumn{5}{|l|}{11 years } \\
\hline & & \multirow{2}{*}{$\begin{array}{l}\text { Mean BMI } \\
\text { and SD }\end{array}$} & \multicolumn{2}{|c|}{ BMI z-score } & \multicolumn{2}{|c|}{$\begin{array}{l}\text { Overweight } \\
\text { (including obesity) }\end{array}$} & \multirow{2}{*}{$\begin{array}{l}\text { Mean BMI } \\
\text { and SD }\end{array}$} & \multicolumn{2}{|c|}{ BMI z-score } & \multicolumn{2}{|c|}{$\begin{array}{l}\text { Overweight } \\
\text { (including obesity) }\end{array}$} \\
\hline & & & $\beta$ & $95 \% \mathrm{Cl}$ & OR & $95 \% \mathrm{Cl}$ & & $\beta$ & $95 \% \mathrm{CI}$ & $\mathbf{O R}$ & $95 \% \mathrm{Cl}$ \\
\hline \multicolumn{12}{|l|}{ Sex } \\
\hline Girls & 3357 & $15.7(2.02)$ & 0 & & 1 & & $17.9(3.05)$ & 0 & & 1 & \\
\hline Boys & 3751 & $16.3(2.41)$ & 0.30 & 0.25 to 0.36 & 1.72 & 1.50 to 1.98 & $18.9(3.61)$ & 0.48 & 0.42 to 0.54 & 2.08 & 1.85 to 2.34 \\
\hline \multicolumn{12}{|l|}{ Mother's birthplace } \\
\hline Hong Kong & 4632 & $15.9(2.15)$ & 0 & & 1 & & $18.3(3.34)$ & 0 & & 1 & \\
\hline $\begin{array}{l}\text { Mainland China/ } \\
\text { other }\end{array}$ & 2476 & $16.2(2.37)$ & 0.13 & 0.06 to 0.20 & 1.32 & 1.17 to 1.54 & $18.6(3.45)$ & 0.07 & -0.002 to -0.15 & 1.08 & 0.94 to 1.24 \\
\hline \multicolumn{12}{|c|}{ Highest parental education } \\
\hline$\leq 9$ th grade & 2216 & $16.1(2.35)$ & 0 & & 1 & & $18.5(3.56)$ & 0 & & 1 & \\
\hline $\begin{array}{l}10 \text { th to } 11 \text { th } \\
\text { grade }\end{array}$ & 3084 & $16.0(2.27)$ & 0.02 & -0.05 to 0.09 & 0.97 & 0.85 to 1.18 & $18.4(3.38)$ & -0.02 & -0.09 to 0.06 & 0.98 & 0.86 to 1.13 \\
\hline$\geq 12$ th grade & 1808 & $15.9(2.05)$ & -0.01 & -0.09 to 0.08 & 0.89 & 0.73 to 1.09 & $18.2(3.12)$ & -0.06 & -0.15 to 0.04 & 0.78 & 0.66 to 0.92 \\
\hline \multicolumn{12}{|c|}{ Neighbourhood median income (monthly) $\dagger$} \\
\hline$\geq \mathrm{HK} \$ 30000$ & 538 & $15.8(2.05)$ & 0 & & 1 & & $18.1(3.08)$ & 0 & & 1 & \\
\hline $\begin{array}{l}\text { HK\$20000 to } \\
\text { HK\$30000 }\end{array}$ & 1938 & $16.0(2.24)$ & 0.07 & -0.05 to 0.19 & 1.23 & 0.91 to 1.67 & $18.4(3.33)$ & 0.05 & -0.08 to 0.19 & 1.06 & 0.83 to 1.36 \\
\hline $\begin{array}{l}\text { HK\$10000 to } \\
\mathrm{HK} \$ 20000\end{array}$ & 4595 & $16.0(2.28)$ & 0.08 & -0.03 to 0.20 & 1.27 & 0.94 to 1.69 & $18.4(3.45)$ & 0.06 & -0.07 to 0.19 & 1.09 & 0.86 to 1.39 \\
\hline$<\mathrm{HK} \$ 10000$ & 37 & $15.7(2.04)$ & -0.21 & -0.83 to 0.40 & 0.44 & 0.06 to 3.45 & $18.6(4.12)$ & -0.21 & -0.99 to 0.58 & 2.18 & 0.67 to 7.16 \\
\hline
\end{tabular}

${ }^{*}$ Adjusted for all covariables in the table.

tUS $\$ 1$, HK\$7.8

Table 2 Joint associations of highest parental education and mother's birthplace with BMI z-score and overweight (including obesity) at 6-11 years nested by child and adjusted and stratified by sex

\begin{tabular}{|c|c|c|c|c|c|c|c|c|c|c|}
\hline & \multirow{4}{*}{$\begin{array}{l}\text { Sex } \\
\text { All }\end{array}$} & \multirow{4}{*}{$\begin{array}{l}\begin{array}{l}\text { Mother's } \\
\text { birthplace }\end{array} \\
\text { Hong Kong }\end{array}$} & \multicolumn{6}{|c|}{ Highest parental education } & \multirow{4}{*}{$\begin{array}{l}\begin{array}{l}\mathbf{p} \text { Value for } \\
\text { trend }\end{array} \\
<0.01\end{array}$} & \multirow{3}{*}{$\begin{array}{l}\text { p Value for } \\
\text { interaction between } \\
\text { highest parental } \\
\text { education and } \\
\text { mother's birthplace }\end{array}$} \\
\hline & & & \multicolumn{2}{|c|}{$\leq 9$ th grade } & \multicolumn{2}{|c|}{ 10th to 11 th grade } & \multicolumn{2}{|c|}{$\geq 12$ th grade } & & \\
\hline & & & \multicolumn{2}{|c|}{$\beta$ 95\% Cl } & \multicolumn{2}{|c|}{$\beta \mathbf{9 5 \%} \mathbf{C l}$} & \multicolumn{2}{|c|}{$\beta \mathbf{9 5 \%} \mathbf{C l}$} & & \\
\hline \multirow[t]{10}{*}{ BMI z-score } & & & 0 & & -0.07 & -0.17 to 0.02 & -0.15 & -0.25 to -0.05 & & \\
\hline & & $\begin{array}{l}\text { Mainland China/ } \\
\text { other }\end{array}$ & -0.01 & -0.12 to 0.10 & 0.05 & -0.07 to 0.16 & 0.17 & 0.01 to 0.34 & 0.04 & 0.001 \\
\hline & & $\mathrm{p}$ Value & 0.91 & & 0.02 & & $<0.01$ & & & \\
\hline & Boys & Hong Kong & 0 & & -0.02 & -0.17 to 0.13 & -0.12 & -0.28 to 0.04 & 0.06 & \\
\hline & & $\begin{array}{l}\text { Mainland China/ } \\
\text { other }\end{array}$ & 0.05 & -0.12 to 0.23 & 0.14 & -0.03 to 0.32 & 0.27 & 0.01 to 0.53 & 0.11 & 0.01 \\
\hline & & p Value & 0.55 & & 0.04 & & $<0.01$ & & & \\
\hline & Girls & Hong Kong & 0 & & -0.15 & -0.28 to -0.02 & -0.18 & -0.31 to -0.04 & 0.01 & \\
\hline & & $\begin{array}{l}\text { Mainland China/ } \\
\text { other }\end{array}$ & -0.08 & -0.23 to 0.07 & -0.07 & -0.23 to 0.08 & 0.04 & -0.19 to 0.26 & 0.45 & 0.05 \\
\hline & & $\mathrm{p}$ Value & 0.32 & & 0.28 & & 0.04 & & & \\
\hline & & & \multicolumn{2}{|c|}{ OR $95 \%$ Cl } & \multicolumn{2}{|c|}{ OR $95 \%$ CI } & \multicolumn{2}{|c|}{ OR $95 \% \mathrm{CI}$} & & \\
\hline \multirow{9}{*}{$\begin{array}{l}\text { Overweight } \\
\text { (including } \\
\text { obesity) }\end{array}$} & All & Hong Kong & 1 & & 0.87 & 0.74 to 1.03 & 0.65 & 0.54 to 0.79 & $<0.01$ & \\
\hline & & $\begin{array}{l}\text { Mainland China/ } \\
\text { other }\end{array}$ & 0.92 & 0.76 to 1.12 & 0.98 & 0.80 to 1.20 & 1.001 & 0.76 to 1.32 & 0.42 & 0.003 \\
\hline & & $\mathrm{p}$ Value & 0.38 & & 0.18 & & $<0.01$ & & & \\
\hline & Boys & Hong Kong & 1 & & 0.97 & 0.78 to 1.21 & 0.74 & 0.57 to 0.94 & 0.01 & \\
\hline & & $\begin{array}{l}\text { Mainland China/ } \\
\text { other }\end{array}$ & 1.02 & 0.79 to 1.32 & 1.19 & 0.91 to 1.55 & 1.15 & 0.79 to 1.67 & 0.25 & 0.02 \\
\hline & & p Value & 0.93 & & 0.07 & & 0.01 & & & \\
\hline & Girls & Hong Kong & 1 & & 0.72 & 0.55 to 0.93 & 0.55 & 0.40 to 0.74 & $<0.01$ & \\
\hline & & $\begin{array}{l}\text { Mainland China/ } \\
\text { other }\end{array}$ & 0.79 & 0.58 to 1.08 & 0.71 & 0.51 to 0.99 & 0.79 & 0.49 to 1.26 & 0.78 & 0.07 \\
\hline & & p Value & 0.14 & & 0.95 & & 0.14 & & & \\
\hline
\end{tabular}

${ }^{*}$ Mean difference in z-score relative to $2007 \mathrm{WHO}$ growth references at the age of 8.5 years; a difference in 1 unit change in BMI z-score is approximately equal to

$1.8 \mathrm{~kg} / \mathrm{m}^{2}$ in boys, and a difference in 1 unit change in BMI z-score is approximately equal to $2.1 \mathrm{~kg} / \mathrm{m}^{2}$ in girls 
Appendix table 1 Complete case analysis $(n=5999)$ showing joint associations of highest parental education and mother's birthplace with BMI z-score and overweight (including obesity) at 6-11 years nested by child and adjusted and stratified by sex

\begin{tabular}{|c|c|c|c|c|c|c|c|c|c|c|}
\hline \multirow{3}{*}{ BMI z-score } & \multirow{3}{*}{$\begin{array}{l}\text { Sex } \\
\text { All }\end{array}$} & \multirow{3}{*}{$\begin{array}{l}\text { Mother's birthplace } \\
\text { Hong Kong }\end{array}$} & \multicolumn{6}{|c|}{ Highest parental education } & \multirow{3}{*}{$\begin{array}{l}\text { p Value for } \\
\text { trend }\end{array}$} & \multirow{3}{*}{$\begin{array}{l}p \text { Value for } \\
\text { interaction }\end{array}$} \\
\hline & & & \multirow{2}{*}{\multicolumn{2}{|c|}{$\begin{array}{l}\leq 9 \text { th grade } \\
\beta 95 \% \mathrm{Cl}\end{array}$}} & \multirow{2}{*}{\multicolumn{2}{|c|}{$\begin{array}{l}\text { 10th to } 11 \text { th grade } \\
\beta 95 \% \mathrm{Cl}\end{array}$}} & \multirow{2}{*}{\multicolumn{2}{|c|}{$\begin{array}{l}\geq 12 \text { th grade } \\
\beta 95 \% \mathrm{CI}\end{array}$}} & & \\
\hline & & & & & & & & & & \\
\hline & & Mainland China/other & -0.004 & -0.12 to 0.11 & 0.03 & -0.09 to 0.16 & 0.18 & 0.01 to 0.36 & 0.07 & 0.002 \\
\hline & & $\mathrm{p}$ Value & \multicolumn{2}{|l|}{0.96} & \multicolumn{2}{|l|}{0.01} & \multicolumn{2}{|l|}{$<0.01$} & & \\
\hline & Boys & Hong Kong & 0 & & -0.04 & -0.19 to -0.11 & -0.15 & -0.31 to 0.01 & 0.06 & \\
\hline & Girls & Hong Kong & 0 & & -0.18 & -0.31 to -0.04 & -0.22 & -0.36 to -0.07 & 0.004 & \\
\hline & & Mainland China/other & -0.10 & -0.25 to 0.06 & -0.10 & -0.26 to 0.07 & 0.03 & -0.20 to 0.25 & 0.44 & 0.05 \\
\hline & & $\mathrm{p}$ Value & & & \multicolumn{2}{|l|}{0.24} & \multicolumn{2}{|l|}{0.02} & & \\
\hline & & & \multicolumn{2}{|c|}{ OR 95\% CI } & OR 95 & & OR 95 & & & \\
\hline \multirow{7}{*}{$\begin{array}{l}\text { 0verweight } \\
\text { (including } \\
\text { obesity) }\end{array}$} & All & Hong Kong & 1 & & 0.82 & 0.69 to 0.98 & 0.61 & 0.50 to 0.74 & $<0.01$ & \\
\hline & Boys & Hong Kong & 1 & & 0.90 & 0.81 to 1.01 & 0.83 & 0.74 to 0.93 & 0.004 & \\
\hline & & Mainland China/other & 0.99 & 0.89 to 1.12 & 1.03 & 0.91 to 1.17 & 1.20 & 1.01 to 1.43 & 0.36 & 0.03 \\
\hline & & $\mathrm{p}$ Value & 0.99 & & 0.05 & & 0.01 & & & \\
\hline & Girls & Hong Kong & 1 & & 0.68 & 0.52 to 0.90 & 0.49 & 0.36 to 0.67 & $<0.01$ & \\
\hline & & Mainland China/other & 0.76 & 0.55 to 1.04 & 0.69 & 0.49 to 0.97 & 0.79 & 0.49 to 1.27 & 0.90 & 0.09 \\
\hline & & $\mathrm{p}$ Value & 0.09 & & 0.99 & & 0.09 & & & \\
\hline
\end{tabular}

* Mean difference in z-score relative to $2007 \mathrm{WHO}$ growth references at the age of 8.5 years; a difference in 1 unit change in BMI z-score is approximately equal to $1.8 \mathrm{~kg} / \mathrm{m}^{2}$ in boys, and a difference in 1 unit change in BMI z-score is approximately equal to $2.1 \mathrm{~kg} / \mathrm{m}^{2}$ in girls.

of Hong Kong-born mothers and the clearest positive association in the sons of China mainland-born mothers. A complete case analysis produced similar results (Appendix table 1).

\section{DISCUSSION}

In this recently developed, population-representative Chinese birth cohort, we found no clear association between SEP of the family or neighbourhood and childhood BMI in the total sample, perhaps because the associations varied with pathway through socio-economic development. A negative association between family SEP and BMI was most obvious in children whose families had had longer experience of socio-economic development, as indicated by a mother born in Hong Kong, with a mean BMI at 8.5 years about $0.22 \mathrm{~kg} / \mathrm{m}^{2}$ lower in the most educated compared with the least educated. This corresponds to weight lower by about $0.37 \mathrm{~kg}$ for a child of average height. In contrast, among children whose families had least experience of socio-economic development, family SEP was positively associated with BMI, with a mean BMI at 8.5 years about $0.35 \mathrm{~kg} / \mathrm{m}^{2}$ higher, corresponding to a weight higher by about $0.58 \mathrm{~kg}$ for a child of average height. There was no clear association of neighbourhood SEP with BMI.

Despite using a large population-representative birth cohort with high follow-up, our study has some limitations. First, about $16 \%$ of children had incomplete baseline data at first MCHC visit, for which multiple imputations were used. In addition, a complete case analysis produced similar results. Second, we used the mother's birthplace as a proxy for pathway through the socio-economic transition because a large number of new immigrants from China in Hong Kong currently are the wives of Hong Kong residents. ${ }^{24} \mathrm{~A}$ better proxy might have been a more detailed measure of the number of generations both parents' families had spent in a developed environment. However, we do not yet have such information. Third, we do not have maternal
BMI which is associated with childhood obesity. ${ }^{272930}$ However, most women in Hong Kong are not overweight. ${ }^{31}$ Fourth, we did not explicitly consider factors that may be socially patterned and may also affect BMI, such as ill health, because our focus was the social patterning of BMI itself. Moreover, we have only recently re-established direct contact with this cohort, so we do not have detailed information on their health status in childhood. However, ill health is unlikely to explain the different associations between SEP and BMI by mother's place of birth. Finally, Hong Kong is a densely populated city, so we cannot make any comparison between rural and urban settings.

To our knowledge, there are no studies directly comparable with ours. Nevertheless; our findings in the children of mothers born in China mainland are consistent with observations from urban China, where a higher SEP is associated with adiposity. ${ }^{15}$ They are also consistent with observations for immigrants and minorities in developed populations. ${ }^{13} 14$ Similarly our findings in the children of Hong Kong-born mothers are consistent with the studies from long-developed, westernised countries. ${ }^{11}$ On the other hand, our findings are somewhat less consistent with the observation that the association of low SEP with adiposity emerges more quickly in women than men as income levels rise with the economic transition, ${ }^{15}$ as we found no clear differences by sex. However, we have previously suggested that pubertal influences, mediated by sex steroids, are relevant to the sex-specific patterns of disparities in obesity that emerge with economic transition. ${ }^{32-34}$ Currently, our cohort are too young for such pubertal influences to have exerted any effect. Finally, our findings are also less consistent with the association also seen in such locations between higher BMI and lower-income neighbourhoods. ${ }^{15} 35$ There are several possible explanations for our findings.

The lack of association between SEP of the neighbourhood and BMI may be a reflection of Hong Kong's geography and 
history. Hong Kong is very small with a high population density and a well-established transport infrastructure, thereby allowing for ease of movement between neighbourhoods. ${ }^{25}$ In addition, short housing tenure and little zoning of school catchment areas may mean that children living in the same neighbourhood may not share the same experiences and exposures. ${ }^{25}$ In addition, the Hong Kong population was formed by migration from southern China in the mid-20th century, with most housing being quite recent and concentrated in new towns established in the last 20 or 30 years. ${ }^{18}$ As such, almost all communities in Hong Kong are relatively new and may not yet have developed a cohesive identity.

Differences in the association of family SEP with BMI by mother's birthplace suggest that the underlying mechanism extends beyond access to resources. Women born in Hong Kong may have a more 'westernised' outlook and stronger perception that slimness is desirable. ${ }^{36}$ However, to what extent these social attitudes determine BMI in children is debatable, although children of this age would be strongly influenced by their parents. Moreover, whether these social attitudes are more than a reflection of actual social norms is rarely considered. Finally, for these social attitudes to have different associations with childhood BMI by family SEP requires some socially structured diffusion of innovations. ${ }^{37}$

Social pressures affecting body weight may also be augmented by physiological processes, which make some children with a very rapid family history of economic transition more vulnerable in an obesogenic environment. With several generations of socio-economic development and higher SEP, birth weight could be higher, and the compensatory infant growth, often associated with childhood adiposity that may occur in lighter-born children, could be less pronounced. However, in Hong Kong, although birth weight is associated with family SEP, ${ }^{35}$ it is also higher in children of non-Hong Kong-born mothers. ${ }^{35}$ Alternatively, there could be an endocrinological pathway in early infancy, perhaps mediated by the simultaneous leptin surge, which may play a regulatory role in the hypothalamus for lifelong appetite control. ${ }^{38}$ To what extent this is mediated by social and environmental influences on mothers postpartum, such as traditional practices after child birth, in pregnancy or at earlier life stages is as yet unclear. Nevertheless, effects on the early infancy leptin surge mediated by cultural practices and earlier living conditions of the mother or previous generations of her family would provide a potential, if very speculative, biological explanation.

\section{CONCLUSION}

Our findings from a population with a recent history of economic development suggest little consistent association between lower family and neighbourhood SEP and higher childhood BMI, perhaps because other factors such as the pathway through socio-economic development may also play a role possibly for cultural or biological reasons. Clarifying the relative importance of these factors is the key to the development of effective interventions for the growing epidemic of adiposity. Nevertheless, without further information, our findings clearly demonstrate the importance of ensuring that any interventions in our and similar settings take into account the heterogeneity of the social patterning of overweight and obesity.

Acknowledgements The authors thank colleagues at the Student Health Service and Family Health Service of the Department of Health for their assistance and collaboration. The authors also thank C Hui for her assistance with the record linkage.

Funding The initial study was supported by the Hong Kong Healthcare $f$ Promotion Fund Committee in Hong Kong (Grant no 216106). Retrieval of additional data in 2005-2006 was funded by the Health and Health Services Research Fund in Hong Kong (Grant no 03040711). Retrieval of geo-spatial identifiers was funded by the Research Fund for the Control of Infectious Diseases in Hong Kong (Grant no 04050172). Recent re-establishment of contact with cohort members was funded by the University Research Committee SRT of Public Health Granted Research, The University of Hong Kong.

\section{Competing interests None.}

Ethics approval Ethics approval was provided by the University of Hong KongHospital Authority Hong Kong West Cluster Joint Institutional Review Board and the Ethics Committee of the Department of Health, Government of the Hong Kong SAR.

Provenance and peer review Not commissioned; externally peer reviewed.

\section{REFERENCES}

1. World Health Organization. Global Strategy on Diet, Physical Activity and Health. http://www.who.int/dietphysicalactivity/childhood/en/2008. Last accessed date: March 62009.

2. Weiss R, Dziura J, Burgert TS, et al. Obesity and the metabolic syndrome in children and adolescents. N Eng/ J Med 2004;350:2362-74.

3. Viner RM, Segal TY, Lichtarowicz-Krynska E, et al. Prevalence of the insulin resistance syndrome in obesity. Arch Dis Child 2005;90:10-14.

4. Sinha R, Fisch G, Teague B, et al. Prevalence of impaired glucose tolerance among children and adolescents with marked obesity. N Engl J Med 2002;346:802-10.

5. Tounian P, Aggoun Y, Dubern B, et al. Presence of increased stiffness of the common carotid artery and endothelial dysfunction in severely obese children: a prospective study. Lancet 2001;358:1400-4.

6. Berenson GS, Srinivasan SR, Bao W, et al. Association between multiple cardiovascular risk factors and atherosclerosis in children and young adults. The Bogalusa Heart Study. N Eng/ J Med 1998;338:1650-6.

7. Reilly JJ, Methven E, McDowell ZC, et al. Health consequences of obesity. Arch Dis Child 2003;88:748-52.

8. Baker JL, Olsen LW, Sørensen TI. Childhood body-mass index and the risk of coronary heart disease in adulthood. N Eng/ J Med 2007;357:2329-37.

9. Hu FB, Wang B, Chen C, et al. Body mass index and cardiovascular risk factors in a rural Chinese population. Am J Epidemiol 2000;151:88-97.

10. Calle EE, Rodriguez C, Walker-Thurmond K, et al. Overweight, obesity, and mortality from cancer in a prospectively studied cohort of U.S. adults. N Engl J Med 2003;348:1625-38.

11. Shrewsbury V, Wardle J. Socioeconomic status and adiposity in childhood: a systematic review of cross-sectional studies 1990-2005. Obesity (Silver Spring) 2008;16:275-84.

12. Sobal J, Stunkard AJ. Socioeconomic status and obesity: a review of the literature. Psychol Bull 1989;105:260-75.

13. Wang $\mathbf{Y}$, Zhang 0 . Are American children and adolescents of low socioeconomic status at increased risk of obesity? Changes in the association between overweight and family income between 1971 and 2002. Am J Clin Nutr 2006;84:707-16.

14. Van Hook J, Balistreri KS. Immigrant generation, socioeconomic status, and economic development of countries of origin: a longitudinal study of body mass index among children. Soc Sci Med 2007;65:976-89.

15. McLaren L. Socioeconomic status and obesity. Epidemiol Rev 2007;29:29-48

16. Monteiro CA, Conde WL, Lu B, et al. Obesity and inequities in health in the developing world. Int J Obes Relat Metab Disord 2004;28:1181-6.

17. Yoon YS, Oh SW, Park HS. Socioeconomic status in relation to obesity and abdominal obesity in Korean adults: a focus on sex differences. Obesity (Silver Spring) 2006;14:909-19.

18. Tsang SYS. A modern history of Hong Kong, 1841-1997. Hong Kong: Hong Kong University Press, 2004.

19. Maddison A. The World Economy: A Millennial Perspective. Paris, France: Development Centre of the Organisation for Economic Co-operation and Development, 2001.

20. Census and Statistics Department Hong Kong. Chapter 2: Marriage, Fertility and Family Conditions - Women and Men in Hong Kong - Key Statistics. The Government of Hong Kong SAR editor, 2008.

21. Hui LL, Schooling CM, Leung SS, et al. Birth weight, infant growth, and childhood body mass index: Hong Kong's children of 1997 birth cohort. Arch Pediatr Adolesc Med 2008;162:212-18.

22. Government oHKST. Department of Health Annual Report, 1997-1998.

23. Harrell FE. Regression modeling strategies: with applications to linear models, logistic regression, and survival analysis. New York, USA: Springer Verlag, 2001.

24. Lou VW0, Chan CLW. Social Integration of New Immigrants from Mainland China in Hong Kong--A Resilience Approach, 2003.

25. Wong I0, Cowling BJ, Lo SV, et al. A multilevel analysis of the effects of neighbourhood income inequality on individual self-rated health in Hong Kong Soc Sci Med 2009;68:124-32. 
26. World Health Organization. The WHO Child Growth Standards. http://www.who. int/childgrowth/standards/en/2008. Last accessed date: March 62009.

27. Whitaker RC, Wright JA, Pepe MS, et al. Predicting obesity in young adulthood from childhood and parental obesity. N Engl J Med 1997;337:869-73.

28. Schafer JL. Multiple imputation: a primer. Stat Methods Med Res 1999:8:3-15.

29. Lake JK, Power C, Cole TJ. Child to adult body mass index in the 1958 British birth cohort: associations with parental obesity. Arch Dis Child 1997;77:376-81.

30. Guillaume M, Lapidus L, Beckers F, et al. Familial trends of obesity through three generations: the Belgian-Luxembourg child study. Int J Obes Relat Metab Disord 1995;19(Suppl 3):S5-9.

31. Tackling Obesity: Its Causes, the Plight and Prevention Actions. Hong Kong: Central Health Education Unit, Centre for Health Protection, Department of Health, 2005:13.

32. Schooling CM, Jiang CQ, Lam TH, et al. Life-course origins of social inequalities in metabolic risk in the population of a developing country. Am J Epidemiol 2008;167:419-28.
33. Schooling CM, Lam TH, Ho SY, et al. Does economic development contribute to sex differences in ischaemic heart disease mortality? Hong Kong as a natural experiment using a case-control study. BMC Public Health

2008;8:32.

34. Schooling CM, Leung GM. A sociobiological explanation for social disparities in non-communicable chronic diseases-the product of history? J Epidemiol Community Health (In press) DOI: 10.1136/jech.2009.099143.

35. Cheung YB, Yip PS. Social patterns of birth weight in Hong Kong, 1984-1997. Soc Sci Med 2001;52:1135-41.

36. Lee $\mathbf{S}$. Fat, fatigue and the feminine: the changing cultural experience of women in Hong Kong. Cult Med Psychiatry 1999;23:51-73.

37. Rogers EM. Diffusion of innovations. 5th edn. New York, USA: Free Press, 2003.

38. Cole TJ. Early causes of child obesity and implications for prevention. Acta Paediatr Suppl 2007;96:2-4. 